\title{
The civil service's gender diversity agenda under the coalition: where have the critical feminist actors gone?
}

\section{Daniel Fitzpatrick ${ }^{1}$ - David Richards ${ }^{2}$}

Published online: 2 April 2019

(c) The Author(s) 2019

\begin{abstract}
This article examines the patterns of gender representation in the UK Civil Service to interrogate the claim that there was a regressive change in the proportion of women in the most senior grades of Whitehall under the UK Coalition Government (2010-2015). It does so by analysing both quantitative data covering civil service employment patterns during the Coalition years, complemented by new, primary qualitative data drawn from interviews conducted by the authors. The article presents an original explanation of these shifting patterns, emphasising the crucial role of 'critical feminist actors' in driving forward gender equality and diversity agendas in Whitehall. It concludes by highlighting dilemmas and risks involved in this agency-based approach to equality and diversity, which relies on the personal drive and commitment of key, senior actors; and at the same time is subject to the vicissitudes of change in personnel and political environment.
\end{abstract}

Keywords Gender diversity · UK civil service - Austerity · Coalition government · Representative bureaucracy

\section{Introduction}

This article examines the representation of women at senior grades in Whitehall under the Conservative-Liberal Democrat Coalition government (2010-2015). The salience of this issue emerges from a wider, critical debate over gender and diversity in the Civil Service during this period. The article is organised around an abductive

Daniel Fitzpatrick

d.fitzpatrick3@aston.ac.uk

David Richards

dave.richards@manchester.ac.uk

1 Aston University, Birmingham, UK

2 University of Manchester, Manchester, UK 
approach. First, it presents a new empirical investigation into the balance of representation between men and women in Whitehall. This is followed by an analysis setting out the drivers behind the shifting gender patterns during the period, which is then situated in a broader theoretical discussion on representative bureaucracy. In so doing, the article makes two distinct contributions: specifically it presents fresh evidence and an explanation as to why, under the Collation, a regressive change occurred in the critical mass of women at the most senior levels in Whitehall; more broadly, it makes a key intervention on the debate on representative bureaucracies and gendered public institutions, by seeking to advance the theory of critical feminist actors and their role in promoting gender diversity. It is organised in four parts:

Part one frames the current issue of gender diversity in Whitehall. This is done by locating the salience of the current debate on Whitehall and gender diversity through both a theoretical discussion of representative bureaucracy and a historical overview of this debate, bounded by two epochs: 1970-1996 and 1997-2010. Part two provides a demographic examination of the shifting patterns in gender representativeness for Whitehall between 2010 and 2015. Part three analyses the data and identifies a regressive change in the critical mass of women at the most senior levels in Whitehall - the so-called Top 200. It then explains why, by drawing on Annesley and Gains' $(2010,2012,2014)$ approach to gender and the core executive. It highlights the crucial role of 'critical feminist actors' in driving forward gender diversity in Whitehall. The analysis is supported by qualitative data drawn from a series of interviews with key senior civil servants. ${ }^{1}$

Part four draws the key findings together through a series of reflections on the wider implications of the research for studies of the UK core executive and, more broadly, other public institutions. Here, it is argued that the importance of individuals as critical feminist actors presents a dilemma for advocates of organisational diversity. The evidence presented in this article suggests that progress on the descriptive representation of women (as well as other under-represented groups) is overly reliant on an agency-based approach emphasising the personal drive and commitment of senior decision-makers. However, our research on the trends in gender representation within the Senior Civil Service (SCS) also indicates that such gains can be institutionally weak, are subject to the vicissitudes of changing personnel and in so doing can be somewhat ephemeral, once these critical feminist actors have exited.

\footnotetext{
1 The interviews were recorded under Chatham House rule. Existing interview and other data also utilised from 'The Changing Role of Central Government Departments' (L124251023) 1995-1998, D. Marsh, D. Richards and M.J. Smith; and 'Labour and the Reform of Whitehall: Inheritance, Transition and Accommodation' (R000222657) 1998-2000, D. Richards and M.J. Smith.
} 


\section{Whitehall and gender diversity in theoretical and historical context}

\section{Framing the issue}

In 2011, gender parity in the most senior grade of permanent secretary in Whitehall was attained for the first time. The date offers a symbolic moment round which to frame the issues set out in this article. The then Cabinet Secretary, Gus O'Donnell was emboldened to declare that the Civil Service had become a 'genuinely meritocratic' organisation (Foster 2016a). He did, however, fail to add that it had taken over 150 years since the Northcote-Trevelyan reforms had ushered in open, competitive exams for Whitehall. Fast-forward to the end of the Coalition Government (2015) and O'Donnell's claim that meritocracy-free of bias (conscious or otherwise) - as the new norm appeared somewhat premature. The headline figure showed that women accounted for more than half of all UK civil servants (at 53.5\%). Yet, a more nuanced examination revealed that the most senior policy roles in Whitehall remained predominantly the preserve of white, middle-class men, with only $38.7 \%$ of women working in the top four pay bands (ONS 2014; Hay Group 2014). At the highest grade of permanent secretary, the earlier gender parity achieved in 2011 had by the midway point of the Coalition vanished, with only four of the 16 (2013) permanent secretaries being women, rising to six by that Government's end.

These shifts in the make-up of Whitehall drew accusations that the gender diversity agenda under the Coalition had been deprioritised. A National Audit Office (2015, p. 7) report concluded that 'momentum was lost'. Labour's Deputy Leader Tom Watson regarded it as 'shameful', while the Shadow Cabinet Office Minister Louise Haigh argued: 'The top brass of the civil service is now more white and more male than at any time in almost two decades and the glass ceiling which was smashed in 2011 when women achieved parity has now been painstakingly reassembled and reinforced' (Foster 2016a). O'Donnell's successor, Jeremy Heywood recognised the figures were 'disappointing' and that they did 'not represent the gender diversity we are determined to achieve' (Foster 2016b). It prompts an important question: was Gus O'Donnell somewhat presumptuous to claim in 2011 that Whitehall had become both an exemplar employer and a meritocratic organisation?

\section{Theorising representative bureaucracy: a brief overview}

To address this crucial issue, it needs positioning first within a wider theoretical context. There is a rich seam of literature on the gendered nature of public bureaucracies, often characterised in terms of both the vertical and horizontal segregations of men and women (Miller and McTavish 2014). The concept of representative bureaucracy posits that public organisations should reflect the demographic composition of the population they serve (Andrews et al. 2014). Moves to enhance the diversity and representativeness of public bureaucracies has become an embedded feature across many liberal democratic states (Newman and Ashworth 2009). Here, theories of representative bureaucracy are crucial in establishing why the promotion 
of gender diversity is justified not only on the moral basis of its intrinsic merit, but also due to its symbolic effects on notions of democratic inclusion, as well as the 'business case' of improved organisational performance via enhanced responsiveness and legitimacy. In so doing, it directly addresses the 'glass ceiling' problem within public organisations (see Naff 1994; Soni 2000; Connell 2006; Kenny 2013).

Early studies on representative bureaucracy focused on the descriptive and symbolic representation of women (Krislov 1974; Mosher 1968). Descriptive representation entails a 'mirroring' effect, whereby the personnel of the public organisation share the same demographic identifiers (gender, race, disability status, sexuality, social class, religion etc.) as the population it serves. In symbolic terms, the representation of women in the public bureaucracy is depicted as standing for the diversity and inclusion of a democratic polity (Pitkin 1967; Saward 2006; Lombardo and Meier 2018).

More recent feminist scholarship has sought to highlight the gendered aspects of political representation, shifting the focus from descriptive and symbolic representation to a critical examination of the various mechanisms through which women's interests can be mobilised (both internal and external to the state). The focus in this feminist research is on policy outcomes that address the subordinate position of women in society and the gendered division of labour and unpaid work (Chappell 2004; Lovenduski 2005; Annesley and Gains 2010). As Chappell (2013, p. 614) observes

Gender does not merely exist in the state, but is also reproduced through it. The products of institutions-laws, policies and rules-are imbued with these internal values and come to shape societal norms and expectations; in this sense gender and institutional outcomes can be seen as co-constitutive and mutually reinforcing.

Central to this set of literature is a key empirical and analytical question: what difference does the representation (in various legislative, administrative and political contexts) of women make to policy outcomes?

Underlying this question is the relationship between descriptive (or passive) and substantive (or active) representation. Substantive representation posits that representatives will actively promote the interests of the demographic group to which they are categorised. In the so-called politics of presence (Philips 1995, 1998), a causal link is established between the descriptive representation of women in an empirical sense and substantive representation, in which female representatives prioritise and express different types of values, attitudes, and policy priorities based on their 'shared experience' in the home, workplace and public sphere (Mansbridge 1999; Lovenduski and Norris 2003). In the literature on representative bureaucracy, it is contested whether the 'shared experiences and values, which may not be shared across gender and race division, fundamentally affect the decisions made by and the actions taken by bureaucrats' (Meier and Nicholson-Crotty 2006). Hypothesising the link between descriptive and substantive representation in the UK SCS is outside the remit of this study; suffice to say, the authors assume that the substantive representation of women's interests is more likely to follow from a significant and sustained presence of women in the higher grades of the civil service (Stokes 2005). 
A review of research on representative bureaucracy reveals that representation at higher levels of office invariably leads to greater substantive representation than at lower levels (Dolan 2001). For descriptive representation to translate into substantive representation, bureaucrats must be able to exercise sufficient discretion to act for underrepresented groups (Marvel and Resh 2015). Research on the relationship between representative bureaucracy and administrative discretion posits a positive correlation between discretion and substantive representation: the link between descriptive and substantive representation becomes stronger as discretion increases (Riccucci and Meyers 2004; Marvel and Resh 2015). Although 'street-level bureaucrats' (Lipsky 1980) enjoy considerable discretion over the implementation of policy and the provision of services due to direct interaction with the public, senior officials have a larger 'sphere of influence' (Meier and Bohte 2001, p. 457) on the strategic direction of the department or agency, regarding recruitment; promotion; flexible working practices; staff well-being; and organisational culture. Those officials operating within the SCS have significant managerial autonomy to represent women actively within and sometimes across Whitehall departments (Wilkins 2006; Sowa and Selden 2003). Dolan (2000, p. 525) claims that for women who 'have already reached the pinnacle of their career service, attitudes or efforts geared towards improving women's status in the workplace may simply be less risky for them'. The institutional context of the UK SCS, therefore, provides a critical case for both the literature on state feminism and representative bureaucracy.

Yet feminist research on the representation of women in the UK civil service remains under-developed. Those studies that are available tend to focus exclusively on the aggregate level (see for example Andrews and Ashworth 2013, 2015). Crucially, beyond Watson's (1994) seminal, but now dated contribution, there is limited research on the gendered nature of Whitehall (cf. Waylen and Chappell 2013). This lacuna is even more surprising given the scale of equality and diversity reforms Whitehall has undergone in the period since Watson's original study.

In the absence of an established canon of literature seeking to contextualise this subject, what instead can be offered is a brief historical overview of the diversity agenda in Whitehall over recent decades. This is framed by two distinct epochs.

\section{0-1996: An era of reform without much progress}

The early 1970s might have been seen as a crucial moment in the development of the diversity agenda in the civil service given the emergence more widely of social regulation in the workplace. ${ }^{2}$ Yet Rodney Lowe's (2011, p. 329) official history of the civil service (1966-1981) suggests Whitehall was:

little affected since it was widely regarded, and regarded itself, as a particularly enlightened employer of women. Since the 1930 s ... there had been no formal discrimination in relation to recruitment; in 1946 the marriage bar had

\footnotetext{
${ }^{2}$ Most notably with the introduction of the Equal Pay Act (1970), the Sex Discrimination Act (1975) and the Employment Protection Act (1975) (Moran 2003).
} 
been lifted; and since 1962 equal pay-denied to some 3 million white-collar workers in the private sector-assured.

Halsey and Crewe (1969) offer evidence that women 'were concentrated in the lower grades of all classes and that married women were typically denied promotion' (Lowe 2011, p. 329). Indirect discrimination was identified as a key issue leading in turn to the theme of equality of opportunity emerging as part of a wider reform agenda for the civil service. The Kemp-Jones (1971) report The Employment of Women in the Civil Service was the first official recognition of the implicit barriers to gender equality and balance in Whitehall, emphasising supply-side issues about the nature of the work and career pathways in the SCS, in conjunction with the hegemonic masculinity of departmental cultures.

Progress on gender diversity, particularly at senior levels, was limited throughout the 1970s and 1980s (see Richards 1997; Marsh et al. 2001; Kavanagh and Richards 2003). Kavanagh and Richards' (2003, p. 185) demographic study of the period reveals 'a high degree of continuity between officials promoted in the 1970s and their successors in the 1980s ... the SCS continued to be the preserve of an all-male, Oxbridge educated, upper to middle classes elite'. Formal recognition that women continued to be concentrated in the lower grades of the civil service prompted a series of equal opportunity initiatives by the Cabinet Office over the next two decades (Watson 1994).

In 1996, following recommendations in the 1994 White Paper, 'Continuity and Change', the SCS was established, replacing the old unified grading structure at grade level 5 and above. ${ }^{3}$ The objective was to establish a flatter and more flexible management structure with 'more scope for talented individuals to make their mark' (Cm. 2627, 4.6, p. 17). It included a commitment to monitoring equal opportunities for under-represented groups to progress into and through to the SCS. Along with the improving gender balance of Fast Stream recruits (Devanny and Haddon 2015; Wolf 2013; Adam 2017), the introduction of an elite cadre of top officials was linked to a steady rise in the number of women entering the higher grades of the civil service (see Fig. 1). These mid-1990s reforms were subsequently built on by the New Labour Government, where the saliency of the gender diversity rose up the political agenda.

\section{The New Labour years: 1997-2010}

New Labour identified the narrow, demographic make-up of Whitehall as a key issue. It sought to ensure the Civil Service reflected 'the full diversity of society' as part of its drive to improve governmental capabilities in policy-making and service delivery (Cabinet Office 1999, p. 56). Labour's modernisation agenda for public services included Civil Service reforms addressing gender equality and representation.

\footnotetext{
3 The SCS comprises a group of around 3600 senior officials, including permanent secretaries, directorgenerals and deputy directors in the highest grades of the civil service (previously grade 5 and above) and agency chief executives.
} 


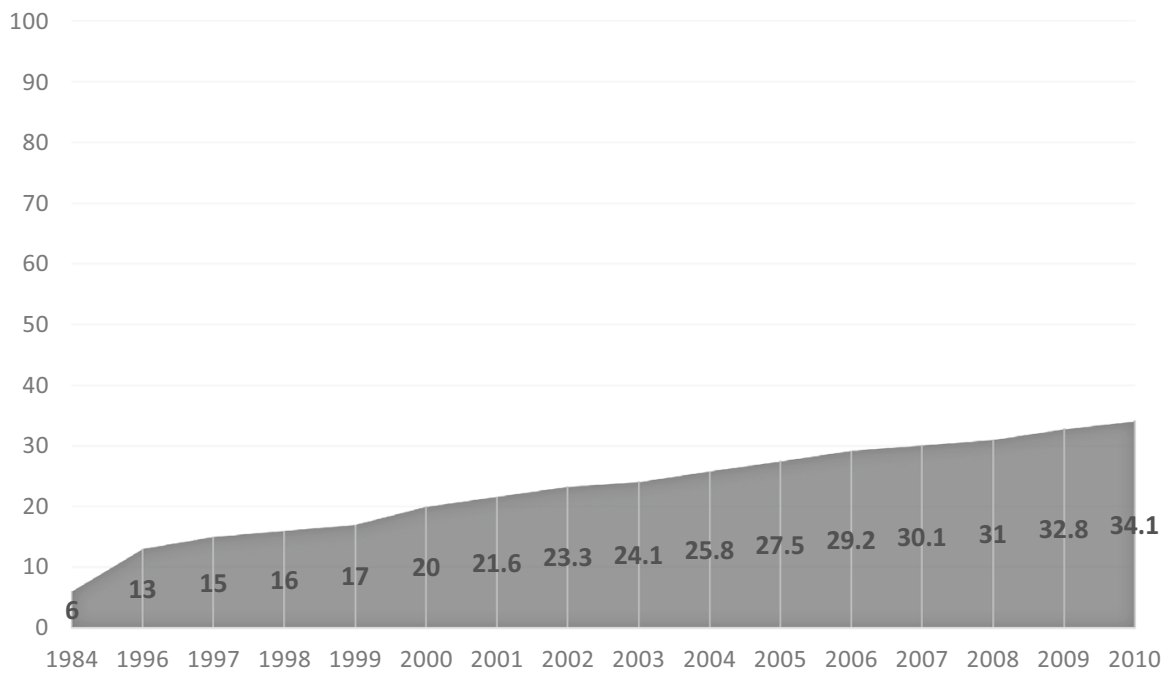

Fig. 1 Representation of Women at Grade 1-5 (Senior Civil Service): 1984-2010 (percentage headcount) Source: The National Archives, Civil Service Statistics

Institutional innovation was introduced with the creation of a new Minister for Women in conjunction with a Women's Policy Unit (later renamed the Women and Equality Unit). Collectively, this formed part of a 'gender mainstreaming' strategy promoted across all departments via a network of officials tasked with disseminating policy guidance on implementation and delivering diversity training (see Squires and Wickham-Jones 2002, 2004). Fiona Reynolds, the first director of the unit, ${ }^{4}$ acknowledged the scale of the task:

the new system has recognised that the old ways are not a sensible way of going about things. This is a job of massive complexity and time and I think it would be extraordinary if the culture of government changed overnight. No one is pretending that there are not setbacks or that the job is not very difficult.

Elsewhere, 'harder' equality standards were included in the first round of Treasury public service agreements (PSAs) with departments. PSA Target 9 (HMT: 2004) on gender equality incorporated measures to improve the representation of women in public life, including specific targets to increase the proportion of women in the SCS to $37 \%$ by 2008 and $30 \%$ in top management posts (Pay bands 2 and 3). The direct targets set for the (descriptive) representation of women in the SCS were presented as a key measure in securing the central aim of PSA Target 9: 'that all institutions with power and influence ... [reflected] ... the diversity of the population as a whole' (Women and Equality Unit 2006, p. 5).

\footnotetext{
${ }^{4}$ In an interview with one of the authors in 1999.
} 


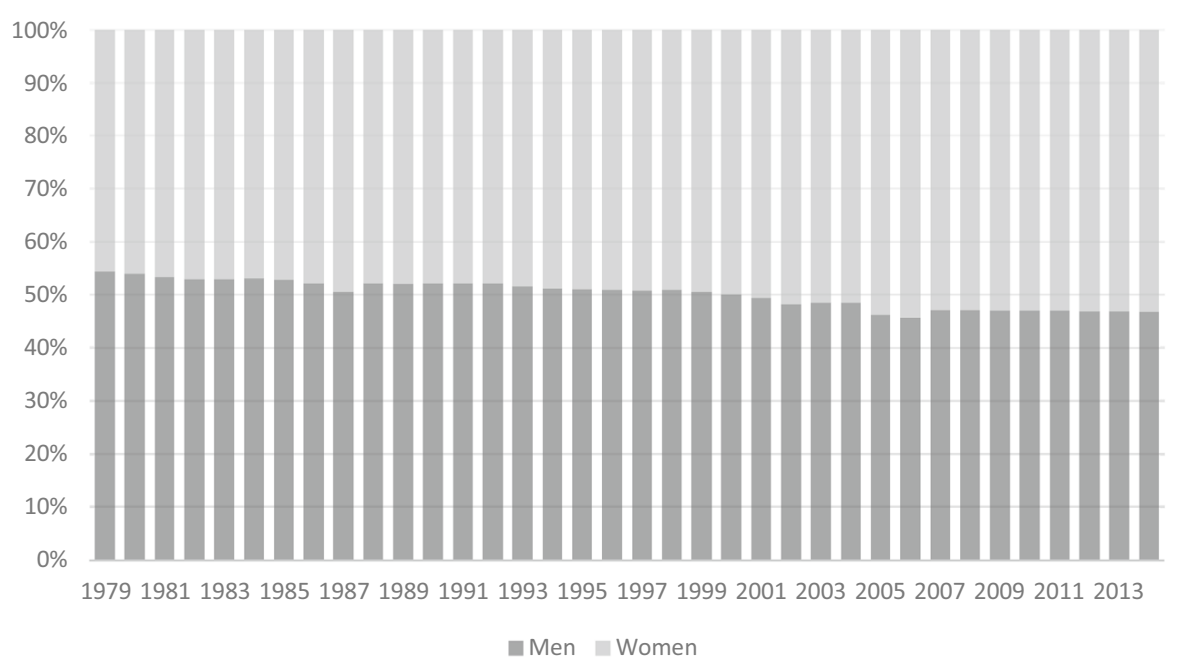

Fig. 2 Gender Balance of the Civil Service in 1979-2014 (percentage, headcount) Source: Devanny and Haddon (2015, p. 11)

The extent to which these New Labour initiatives impacted on the diversity agenda in Whitehall are set out below. Here, the empirical evidenced provided offers a comparative analysis of the subsequent Coalition years.

\section{A demographic survey of gender diversity patterns (1997-2015)}

A longitudinal breakdown of the overall figures in relation to gender balance within Whitehall highlights the gradual shift towards parity over the last 30 years (see Fig. 2).

The focus of this article is on the more senior levels in Whitehall. The headline figures reveal a steady progression in the representation of senior women in Whitehall, during the Labour years. In 1994, six departments had no women at all in the top three grades. Between 1996 and 2010, the overall number of women in the SCS rose from just over 500 to approximately 1500 . In proportional terms, the gender gap between the whole civil service and the SCS considerably narrowed under New Labour (see Fig. 3).

Following the 2008 financial crisis, the Coalition's commitment to reduce public spending led to unprecedented cuts in Whitehall. Between 2010 and 2015, there was a $20 \%$ contraction from 484,000 to 402,000 , reducing the civil service to its lowest level in the post-war era (see ONS 2015, Fig. 4). In comparison, it took three successive Thatcher governments over 11 eleven years to render a $10 \%$ reduction (Diamond 2014).

There was a notable variation in the scale of downsizing across different departments, with the Department for Communities and Local Government (DCLG), experiencing the largest contraction at 35\% (see Fig. 5). 
60

50

40

30

20

10

0

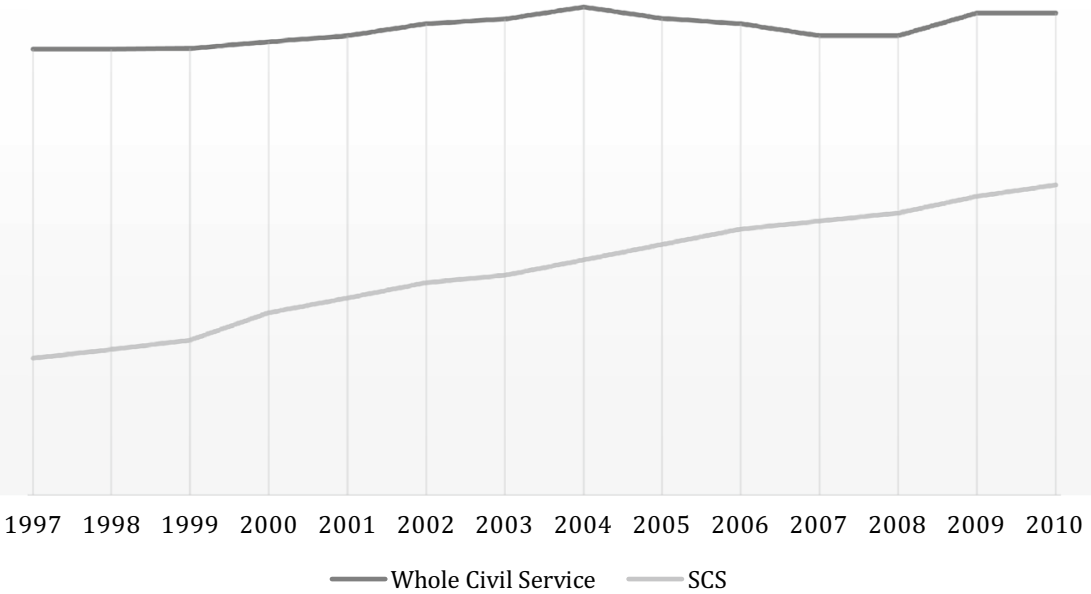

Fig. 3 Representation of women in the UK Civil Service by responsibility level Source: Office for National Statistics, Civil Service Statistics (1997-2010)

$5,40,000$

$5,20,000$

$5,00,000$

$4,80,000$

$4,60,000$

$4,40,000$

$4,20,000$

$4,00,000$
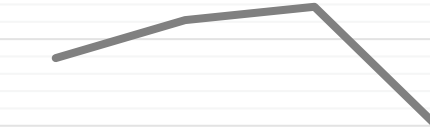


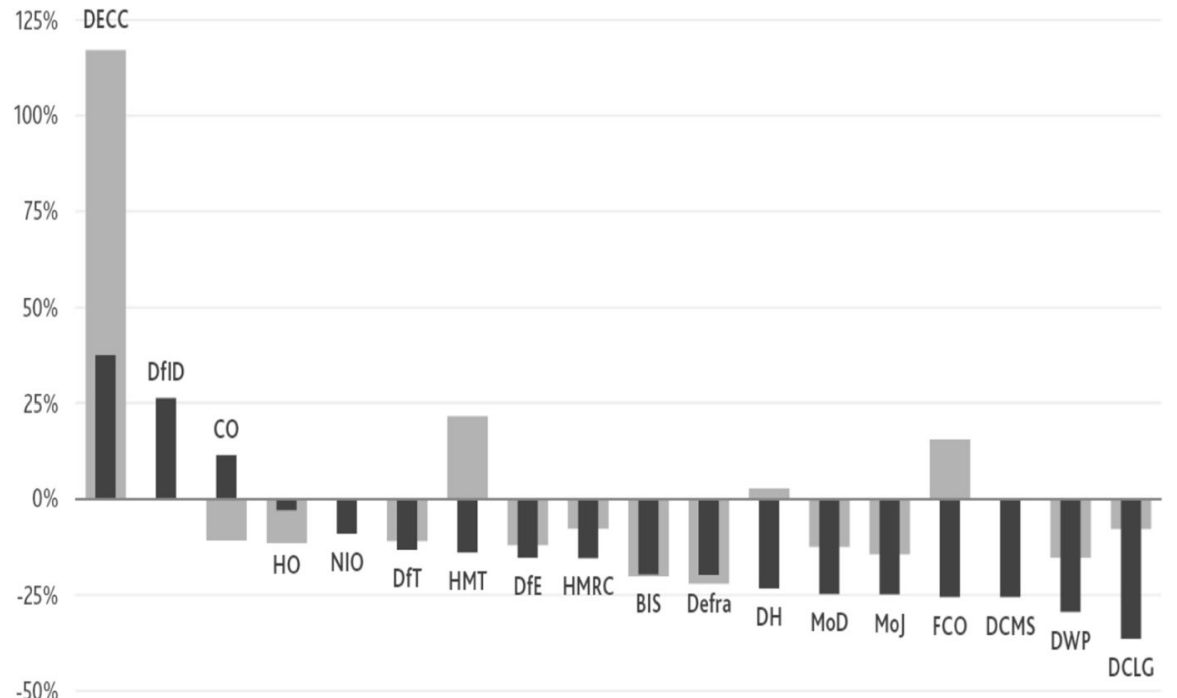

$-50 \%$

\section{Extra-governmental public body $\square$ Department}

Fig. 5 Percentage Change in Staff across Departments (2010-2015) Source: Freeguard et al. (2015, p. 60)

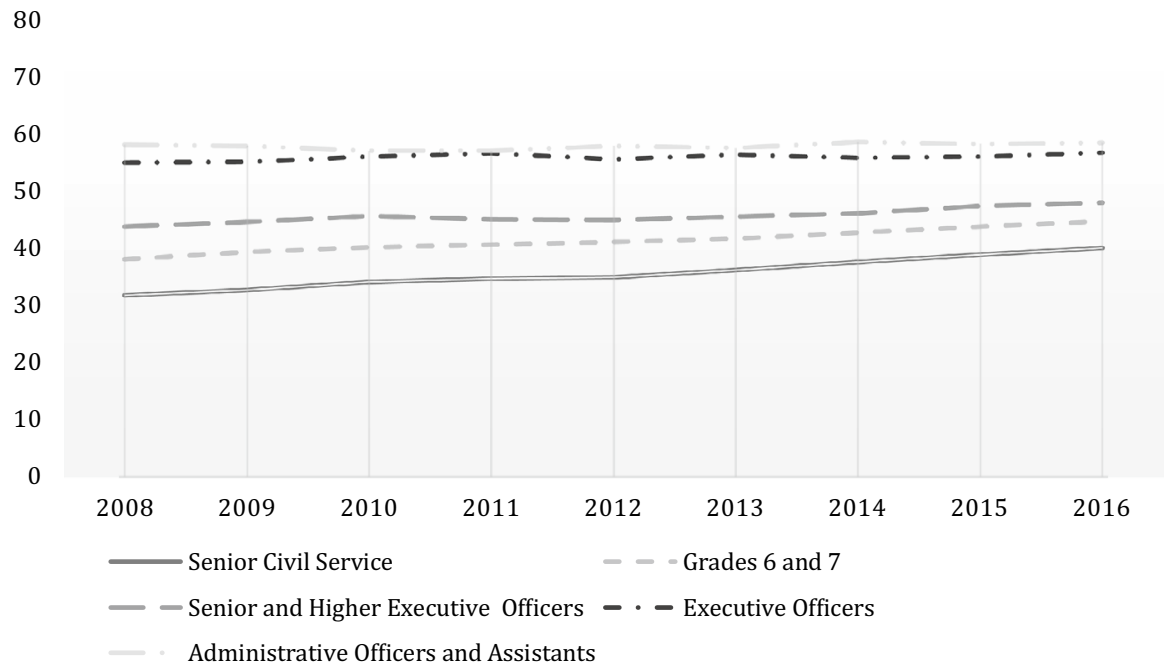

Fig. 6 UK Civil Service employment, proportion of women by responsibility level (2008-2016) Source: Official for National Statistics (2016) 


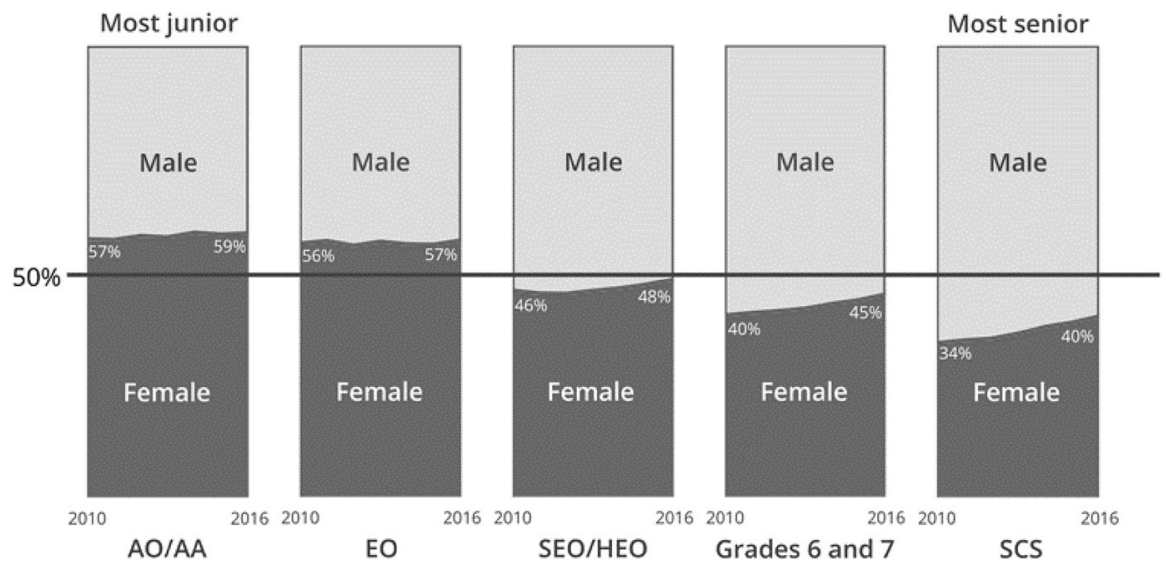

Fig. 7 Gender representation by grade (2010-2015) Source: Freeguard et al. (2017)

appears no observable gendered dimension to the implementation of cuts at a senior level, whether through voluntary or compulsory redundancy (see Fig. 6). The SCS experienced only a small reduction of $4 \%$ with the bulk of the losses occurring in lower grades. Figure 6 highlights the relative increase in the size of the SCS, alongside a marginal increase in the female-to-male ratio in that cohort.

The variation in Civil Service recruitment trends precludes any immediate conclusions on a potential 'austerity effect' in relation to the demographic makeup of Whitehall. If anything, the overall contraction of the civil service coupled with the transition to a more top-heavy public bureaucracy had a favourable effect on the overall gender diversity of Whitehall (see Fig. 7).

What the above data mask is the emergence of a rising gender disparity in the recruitment to the most senior roles in the civil service during the Coalition years. High 'intra-Civil Service churn' (Flinders et al. 2013) has not been reflected by similarly high levels of mobility of under-represented groups into the senior management roles in the Top 200 officials in grades 3 and 4 (DirectorGeneral and Permanent Secretary level or equivalent). By 2015, the net effect was that women only accounted for $30 \%$ of Director-Generals (or equivalent Grade 3 role) and just $12 \%$ of Permanent Secretaries (or equivalent grade 4 role) in the main 16 spending departments in Whitehall (Cabinet Office 2015). So while the SCS gender profile steadily improved, the representation of women in the most senior positions in the civil service, at best, stalled (see Fig. 8).

How might this bifurcation in the trends of gender representation between the most senior positions in Whitehall and the rest of the civil service be accounted for? The following sections explores three conceptual approaches that offer explanatory value: the temporal impact of department austerity; the critical mass approach (Kanter 1977); and the critical actor thesis (Childs and Krook 2008, 2009). 
Figure. Gender representation in the Top 200 (Grades 3 and

4)

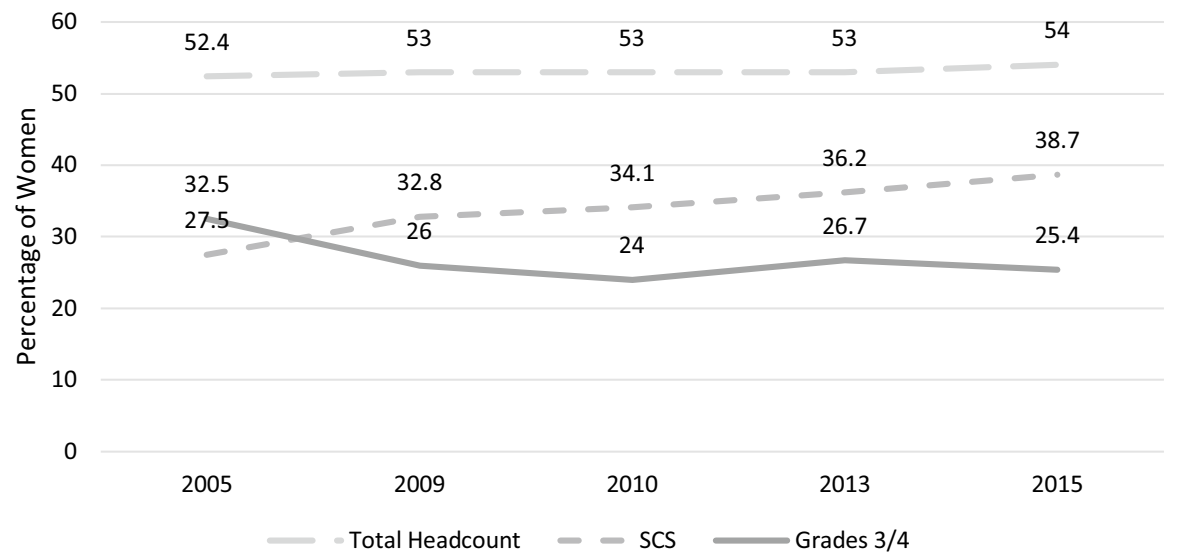

Fig. 8 Gender representation in the Top 200 Source: Office for National Statistics, Civil Service Statistics (2005-2015)

\section{Explaining the coalition's approach to gender diversity: what happened to the critical feminist actors?}

What is most notable under the Coalition is the gendered dimension to recruitment at the most senior levels. A series of high-profile, 'early' departures saw several female Permanent Secretaries (including Helen Ghosh, Moira Wallace and Gillian Morgan from their respective leadership of the Home Office, Department of Energy and Climate Change and the Welsh Government) being replaced by men. This reinforced the perception that the appointment of women at the highest grades remained an issue (Healey 2014). The Coalition's perceived 'problem with women' was attested by two separate reports from the Hay Group (2014) and the National Audit Office (2015) which concluded that macho, exclusionary cultures were more prevalent within the upper echelons of Whitehall compared with the rest of the civil service, leading to women 'choosing to opt out of more senior roles in the SCS' (Hay Group 2014, p. 13).

The next section draws on the interview data to explore and analyse the potential drivers behind this dynamic. In total, nine acting female senior civil servants, operating at permanent secretary, director-general and director level, were interviewed between 2013 and 2015. Of these interviews, seven were conducted face-to-face, with two via the telephone. The semi-structured qualitative interviews explored the enablers and disablers of gender diversity in the UK SCS from the standpoint of the female respondents. Using an abductive approach, key themes were developed iteratively via the reading of the existing literature and analysis of the primary interview data. Three key themes were identified: the impact of institutional contraction (imposed by austerity cuts); the importance of critical mass; and the role of critical feminist actors. 


\section{An austerity effect?}

An 'austerity effect' approach prioritises the specific, historic circumstances under which the Coalition Government found itself, emphasising its response to the repercussions of the 2008 financial crisis. It focuses on a potential causal relationship between austerity and gender diversity in Whitehall. The argument here is that cuts in departmental spending curtail promotion opportunities, which fall harder on the range of opportunities available to women, rendering a negative effect on gender diversity (Rafferty 2014; Blum et al. 1994; Cooper and Austin 2012).

Applying this approach to the Coalition years, the notion of a link between austerity and declining gender diversity in the SCS is a theme borne out by qualitative research. For example, Devanny and Haddon's (2015) study reveals a number of officials [they interviewed] and commentators claim as a 'simple fact' that departmental cuts to staff and the recruitment 'freeze' since 2010 had a deleterious impact on opportunities for under-represented groups. This is a view supported by our interviews. So illustratively, one senior official, reflecting on the programme of cuts in personnel, observed that 'since the election in $2010 \ldots$ there's been an active campaign to move out those people who were willing or could be persuaded to go ... so it has altered the make-up of the civil service ... in terms of its gender balance'. Interestingly though, when prompted, none of the interviewees could be specific about the impact of staff retrenchment on the representation of women. As one female director general commented: 'I wouldn't say it's hit us yet ... perhaps because we set out our stall early ... but it [austerity] can't help'.

Elsewhere, the former Treasury Solicitor, Paul Jenkins observed: 'One of the things we were always very conscious of was that as the civil service shrank in size, the opportunities for promotion into the SCS were going to get fewer-and that's undoubtedly happened' (Ross 2014). The lack of officials from underrepresented groups (particularly BME and disabled staff) entering the top grades was seen as an outcome of the 'restriction in the number of opportunities that are there' in the last 4 years (Ross 2014). The implication here is that significant headcount reductions create 'a potentially challenging environment for pursuing a parallel agenda for changing the composition of the workforce' (Devanny and Haddon 2015, p. 42).

Another theme to emerge from the interview data was the heightened pressure on work-life balance post-2010. One director said that departmental cuts had 'led to bigger workloads ... the need to "do more with less" ... which creates real problems for retention'. It can be extrapolated that there were few incentives for women to pursue promotion within the SCS given the increased work pressure and lower financial reward (Brecknell 2013). Evidence from a Cabinet Office (2014) commissioned report supports this view, revealing that $100 \%$ of female respondents cited work-life balance as a factor that would deter them from applying for more senior roles in the SCS.

It is difficult to ascertain the impact of austerity on the gender balance of the civil service between 2010 and 2015. The effect of departmental cuts on the SCS as a single cadre was benign; the representation of women also continued on a similar upward trajectory. Departments that bore the most severe cuts, such as DCLG, did not experience a concomitant fall in the proportion of female senior officials. Other 
departments that grew in size since the 2010 Spending Review, such as the Cabinet Office, still saw a decline of women in senior positions. So while austerity seems to have had a discursive effect on the perception of gender diversity, its impact on the regression in the proportion of women within the Top 200 is not quantifiable.

\section{Beyond a 'critical mass' approach}

What the aggregate data on the Coalition years reveals is an increase in the proportion of women in all grades of the civil service, except within the Top 200 group. The contrast in these two sets of figures raises questions over established 'critical mass' approaches (see Meier 1993). The traditional argument suggests that once critical mass is achieved 'the relationship between passive representation and active representation is constant' (Hindera and Young 1998, p. 656). Temporal delays notwithstanding (Lovecy 2007), the point at which critical mass of women in an organisation is reached is portrayed as a step-change for its culture and working practices. Research by Kanter (1977), for example, argues that women must account for at least $40 \%$ of an organisation, if there is likely to be any impact upon institutional culture, norms and values.

Women make up more than half of the civil service. For the SCS, in 2015, the figure was $38.7 \%$, rising above the putative 'tipping point' of $40 \%$ in 2016 (ONS 2016). Yet, despite this, the qualitative evidence suggests the culture and practices of the SCS were far from being 'feminised' (Studlar and McAllister 2002, p. 234). Our research supports previous empirical studies that question an assumed relationship between 'sheer' numbers of women and discernible changes in outcomes and organisational cultures (Beckwith 2007; Beckwith and Cowell-Meyers 2007).

The increasing proportion of women in the SCS has not been sufficient to prompt a qualitative shift in the gendered norms, rules and practices that characterise the nature of group interactions in Whitehall. The interviews drew varied responses on the issue of the nature of Whitehall culture. One Permanent Secretary said that 'Whitehall could still be a stuffy place, but is probably as inclusive as anywhere else'. Other respondents viewed it in much more gendered terms, commenting that 'the culture of maverick still abounds ... men are seen as risk-takers, while women's are ... just that ... mistakes'. Other studies have identified similar perspectives of a male-dominated environment, particularly within the SCS (Devanny and Haddon 2015; Bagilhole 2002). Respondents to the Cabinet Office (2014, pp. 18, 21) study were more candid, describing the culture of the SCS as a 'bear pit'; 'a hideous male macho culture at the top'; and 'very cut-throat and underhand'. Moreover, a theme of regression is evident. One respondent observed that

Things have changed again particularly over the last 5 years... I have seen the culture become more and more macho. The rise of certain individuals, male, white and hugely opinionated, who do not like anyone questioning them, challenging them has put us back to the dark ages. Women are back to being told they are mouthy, aggressive or not leaders when they disagree or display softer inclusive leadership skills. I have worked at senior level in three departments and have seen this in all (Cabinet Office 2014, p. 21). 
Part of the explanation points to the absence of a critical mass of women at the toppermanent secretary and director-general level—with the evidence above revealing it flat-lined to around $25 \%$ during the Coalition period.

The theory of critical mass has been widely contested (Grey 2002, 2006; Childs and Krook 2008, 2009; Lovenduski 2005; Tremblay 2006). Critics claim it oversimplifies the relationship between the descriptive and substantive representation of women by correlating bold numbers with actual outcomes (Lovenduski 2005; Dahlerup 2006). Given the evidence presented here, it offers, at best, a partial explanation of the complex dynamics during the Coalition years in relation to the issue of gender diversity in Whitehall. What is required is an approach that seeks to theorise the relationship between longer-term trends in women's descriptive representation and the more immediate impact of austerity on the gender-diversity agenda. It is here then that we turn to the contribution by Annesley and Gains (2010, 2012, 2014) as a fuller, more nuanced approach, emphasising the key role played by particular individuals within the core executive as a critical feminist actors.

\section{Bringing in the role of the critical feminist actor}

Annesley and Gains (2010) argue that in Westminster-style democracies, power and resources tend to be concentrated within a small group of actors. In the case of the UK, it is the core executive (see Smith 1999). The notion of the core executive aims to broaden the conception of executive power beyond a narrow focus on key central actors, such as the prime minister and the chancellor, to a wider set of institutions, networks and practices at the heart of the British government machine (Rhodes 1995, 2011; Burch and Holliday 2004; Smith 1999). In developing this approach, Marsh et al. (2001, 2003) observe, it is Whitehall departments that are the 'most important actors in the core executive ... given both the resources and influence that they command' (2001, p. 261). It is claimed that within this particular loci, the dominant resources for agenda setting are located.

From this perspective, there is a need to focus on the currently under-explored role played by departments and more specifically senior civil servants, as critical feminist actors. Those officials operating within the Top 200 have considerable discretion over the direction of their departments and also have significant managerial autonomy to represent women actively within and across the SCS (Wilkins 2006; Sowa and Selden 2003). Melanie Dawes, Permanent Secretary at DCLG, claims that

There is quite a lot that we [sic] can do to make sure that people in leadership roles, making decisions, are more balanced. For example, Permanent Secretaries do have choice about who they bring onto their senior boards from within their overall senior leadership. I took a choice a year ago to bring my HR Director onto my senior team and make it seven rather than six. That immediately upped the ante on the gender front. That kind of choice of who is actually on that board helps. It does not have to be based on grade entirely; it can be based on choice. Sometimes it is a symbol of what you care about. That is why, for me, the representation on those senior teams is something that is a bit more flexible and that we ought to pay more attention to. 
This approach suggests that it is actors from the core executive, rather than the wider legislature, who are crucial in promulgating the substantive representation of women (Annesley and Gains 2010). While this active representation may involve the explicit removal of formal barriers to the recruitment, promotion and retention of women in senior grades, it is increasingly targeted at mitigating the informal gendered 'rules of the game' that still pervade aspects of departmental cultures in Whitehall (Waylen and Chappell 2013). If the preponderance of such gendered institutional cultures is to be redressed, it is essential that the core executive sets a clear agenda on gender diversity in order to enable, rather than constrain, other critical feminist actors within the public bureaucracy.

From the outset, the Coalition was seen as having a policy vacuum on equality and diversity in Whitehall, evidenced by its failure to develop any coherent strategy. In the light of the Coalition government's wider political narrative of a smaller state and fiscal consolidation, equality and diversity commitments were downplayed. The issue of austerity was seen as having a key effect, with gender diversity bring framed as a 'fluffy' luxury for more prosperous times (Brecknell 2013). Pursuing equality and diversity did not fit with the Coalition strategy on fiscal consolidation and a rhetorical disavowal of centrally driven targets. The previous notion that the civil service should be an exemplar on equality and diversity was marginalised by the imperative for the SCS 'to show leadership in saving money' (Macpherson 2010). One senior female civil servant described 'a little bit of hiatus over the last few years ... is [equality and diversity] a priority? Is it not a priority? ... that filters down into departments'. Another senior official remarked

We kind of lost the way a bit when the [Coalition] Government came in. In the sense that ... we are committed to equality and diversity, but then because a diversity strategy was never signed off, there weren't clear priorities put in place around E\&D. There was a kind of move away from targets ... a kind of a dip.

Labour claimed the Coalition had 'lost sight of the diversity agenda in the Civil Service', with representation of women, black and ethnic minorities and the disabled 'stalling or getting worse' (Dugher 2014). The lack of salience attached to gender diversity in Whitehall by the Coalition highlights the precarious nature of 'gender mainstreaming': the 'embedding of gender equality in systems, processes, policies and institutions' (Rees 2006, p. 558). Our approach here follows those who argue that the policy machinery of gender mainstreaming is 'weakly institutionalised and easily dismantled when the political landscape changes' (Annesley and Gains 2010, p. 911). Individuals actors - acting alone or more likely in collaboration with others - are required to do the 'institutional work' (Lawrence et al. 2011) not only in the creation, but also the maintenance, of equality and diversity practices and outcomes.

The role of agency in challenging and transforming the dominant masculine hegemony of Whitehall's structure and culture is crucial. As one permanent secretary explained, 'it is needed for some people to push back ... that creates the space for other to follow behind'. The data analysis above reveals that while progress on the gender diversity can be tracked alongside wider societal changes, improvements overtime in the gender balance of the most senior Whitehall roles cannot be 
assumed. As Devanny and Haddon (2015) state, 'it can't be assumed that because progress has been made and important things have landed that they will then staypeople move on, things change'.

A revealing and recurring theme in our interview data was the crucial role played by Gus O'Donnell as Cabinet Secretary (2005-2011). The former director-general of the Government Equalities Office, Jonathan Rees, argued that O'Donnell had been the driving force of the diversity agenda in Whitehall: 'He talked about it all the time. He was passionate; he was visible; he was out there' (Rees 2013). Several respondents remarked upon the how his 'personal commitment' and 'drive' was instrumental in the advances in gender diversity. Yet, in the context of the British core executive, as other studies have observed, this raises the issue of personalism; the reliance on individual actors to the detriment of a more embedded and institutionalised approach to reform (Smith et al. 2011). A problem recognised within our interviews 'Gus obviously did great work ... but everything was through the prism of leadership and capability ... the problem is that different people will emphasis different aspects of leadership at different times'.

The relationship between institutional rules (about gender and with gendered effects) and the actors who work within those rules is not mutually exclusive (Lowndes 2014). The relationship between actors and institutions is iterative and dialectical. From a feminist perspective, actors may seek to reinforce or challenge the gendered effects of institutions. The evidence presented here suggests that since 2010, the failure to improve the gender balance at the top of Whitehall is due to the absence of critical feminist actors in the core executive, coupled to a shift in opportunity structures for reform in a climate of austerity.

We argue that developing Annelsey and Gains's (2010) approach to include senior civil servants is necessary to better understand the gendered disposition of the core executive and Civil Service. We posit an iterative relationship between the 'presence' (Lovenduski and Norris 2003) of critical feminist actors within the core executive, the level of descriptive representation of women within the SCS and Whitehall's concomitant capacity to act as a critical actor to lead diversity agenda across the civil service. Changes in the gendered dynamics of the core executive are likely to have a significant bearing on the descriptive representation of women, in terms of the representativeness of the public bureaucracy, given the core executive is the key site and agent of change.

How can we account for the varied trends in gender representation within the SCS between 2010 and 2015? One approach is to focus on critical feminist actors in the preceding period under New Labour. As discussed above, senior actors in the core executive collaborated to introduce a range of reforms that formalised the recruitment and promotion process to the SCS to improve on inclusion and diversity. Despite austerity, the demographic data would suggest that these reforms and initiatives had some success, although departmental variation remained a key feature of women's representation in Whitehall (Devanny and Haddon 2015). Promotion to the top, at the level of director-general and permanent secretary, remains governed by informal 'rules of the game' (Richards 2008). In this context, the role of critical actors becomes more acute. The position of senior critical feminist actors-whether male or female - to recognise and champion talented women in the Top 200 and the 
grades below is crucial. The continued importance of informal networks and patronage (Devanny and Haddon 2015) within this elite cadre means that the absence of such actors has important consequences for gender diversity.

What is potentially revealing is the evidence on the gender imbalance of recruits according to the type of appointments to the Top 200. Data compiled by the Civil Service Commission (CSC) - the independent agency set up to regulate the recruitment of senior officials according to selection on merit-shows that while the proportion of women appointed through external competition has increased over recent years, both internal and 'exceptional' appointments remain male dominated. Appointments made through open competition (advertised publicly) account for only three quarters of overall recruitment to the SCS. The remainder of top posts are recruited through internal competition (only open to existing civil servants) and through 'managed moves', the latter supposedly by exception. Both of these recruitment mechanisms have led to a much higher proportion of men being appointed (CSC 2014). For example, in 2013-2014, 35\% of all recruits to the Top 200 via open external competition were female; however, this figure drops to $13 \%$ when senior civil servants are recruited by exception to the usual recruitment principles (CSC 2014).

For managed moves - which require a compelling business case to be made for an exception to the CSC's Recruitment Principles-the gender imbalance is even clearer: of the requests submitted to the Commission in 2013-2014, 87\% were requests to appoint a male candidate (Paun et al. 2013). Appointments through managed moves are becoming more prevalent, with 35\% of all recruitment in 2013-2014 being made without complying with the legal requirement for selection of merit following fair and open competition (CSC 2014). The increasing use of this more informal method of recruitment can be seen as a consequence of austerity and the Coalition's cull of public bodies, as former agency and quango staff were transferred back into central government. In 2012 for example, there were 5300 exception appointments related to the appointment of staff who worked for an organisation that was transferred into the civil service (CSC 2014, p. 25). If recruitment by exception becomes the norm, it is likely to have significant implications for the gender balance of the SCS. As the Commission (CSC 2014, p. 20) concluded thus: 'Departments appear more likely to choose a male candidate when they are appointing by Exception than they are when recruiting through a fair and open competition'. The routine nature of these 'exceptional' appointments to the top grades in the civil service serve as an example of institutionalised male bias. Despite the formal rules on recruitment designed to promote transparency, equality and diversity, the implicit and informal gender norms continue to operate to preserve many of the same (old) expectations, relationships, and power structures (Waylen and Chappell 2013, p. 607).

\section{Conclusion}

It is nearly a quarter of a century since Sophie Watson's (1994) original, groundbreaking study on the gendered nature of the British civil service. This article has sought to address the subsequent lacuna on gendered studies of the UK bureaucracy. 
Our starting point is to consider the accuracy of the 2011 claim by the former Cabinet Secretary Gus O'Donnell that Whitehall is now an exemplar employer and meritocratic organisation. In so doing, it has drawn together a set of original quantitative and qualitative data on the Civil Service to shed fresh light on what happened to the gender diversity agenda between 2010 and 2015. The study reveals that during this period,

- women in the Civil Service continued to be concentrated in the lower administrative grades, and less well represented in the higher grades;

- there was a continued general upward trajectory of female representation in the SCS between 2010 and 2015;

- this trend masks key issues regarding the promotion of women to the most senior posts in the Top 200 (vertical segregation) and a significant variance between different departments (horizontal segregation);

- moreover, although $40 \%$ of the SCS were women, so constituting a critical mass of female talent in the pipeline, the top positions of permanent secretary and director-general continued to be male-dominated; and

- gender imbalances were more prominent still when appointments by-passed the procedures for free and fair competition.

The article also seeks to explain why, under the Coalition, a regressive change occurred in the critical mass of women at the most senior levels in Whitehall. It draws on Annesley and Gains' work on the gendered nature of the UK core executive to argue there was 'a 'residual effect' caused by the absence of influential critical feminist actors in the core executive between 2010 and 2015, and that this was compounded by an 'austerity effect' that at best led to the downgrading and at worst the marginalisation of the equality and diversity agenda in Whitehall.

These findings also reveal a dilemma for those seeking to address equality and diversity issues. A strategy that predominantly draws only on a 'critical actor' approach is susceptible to an agency-based issue of personalism: an over-reliance on the drive and commitment of key, senior actors; and at the same time subject to the vicissitudes of change in personnel and environment. This was the case during the Coalition years. The departure early on of the critical feminist actor Gus O'Donnell, as Cabinet Secretary, did not then lead to a comparable advocate with similar social capital emerging. At the same time, the environmental setting shifted as an austerity agenda overshadowed all else. What this meant in practice was that the effect of the progressive changes wrought prior to 2010 were subsequently revealed to be somewhat ephemeral and institutionally weak during the Coalition era.

Where then has the story gone since 2015 ? It is premature to make firm judgements on the issue of diversity and gender in Whitehall under the Conservative Administration. In 2015, Whitehall looked to formally institutionalise the gender and diversity agenda through a programme of Permanent Secretary Diversity and Inclusion Objectives (Cabinet Office 2015). Yet, just as austerity played a crucial shaping role between 2010 and 2015, so Brexit is now writ large over all departmental agendas. Whitehall's institutional architecture underwent a redesign with two new departments emerging: the Department for Exiting the European Union [DExEU) 
and the Department for International Trade both originally led by two key 'Brexiteers', respectively. David Davis and Liam Fox, with Boris Johnson at the Foreign Office forming a triumvirate. Subsequently, questions were raised, notably by the Labour Party and the House of Lords Committee for Exiting the European Union, on a potential gender bias in particular, in the senior leadership team under David Davis and concerns about an overly 'macho culture' (see Dunton 2017). Elsewhere, an Institute for Government report (Lily 2017) suggests the continuation since 2015 of the trends identified in our study on the Coalition of a declining percentage of women in the most senior grades in Whitehall. Recognition of this on-going issue prompted Labour to call for the introduction of quotas at permanent secretary level to address a 'lack of diversity at the top tier' (Foster 2016a).

The conclusions drawn from this article identify the need for further research to exploring the variegated nature of equality and diversity policies and practices, and how they are implemented, across individual departments. More qualitative research is required to understand how in a post-Brexit setting and with the increased salience over the debate on gender pay equality, the embedded institutional logics and cultures of departments shape the representation (both descriptive and substantive) and working environment of women. As Marsh et al. (2001) observe, departments are characterised by particular organisational cultures, which reflect both a broader Whitehall culture, as well as their own particular institutional histories of past policy decisions, controversies and relations with the rest of Whitehall and wider civil society. Further research, which unpacks the interplay between the values, culture and external relations of departments and how these are operationalised in selecting and promoting officials in SCS, should be an urgent priority.

Open Access This article is distributed under the terms of the Creative Commons Attribution 4.0 International License (http://creativecommons.org/licenses/by/4.0/), which permits unrestricted use, distribution, and reproduction in any medium, provided you give appropriate credit to the original author(s) and the source, provide a link to the Creative Commons license, and indicate if changes were made.

\section{References}

Acker, J. 1992. From Sex Roles to Gendered Institutions. Contemporary Sociology 21 (5): 565-569.

Adam, R. 2017. The Civil Service Fast Stream in Six Charts. https://www.instituteforgovernment.org.uk/ blog/civil-service-fast-stream-seven-charts. Accessed 8 January 2018.

Alexander Mann Solutions. 2013. Focus on the Pipeline: Engaging the Full Potential of Female Middle Managers. http://www.alexandermannsolutions.com/2012/11/research-focus-on-the-pipelinefe male-managers/. Accessed 20 May 2015.

Andrews, R., and R. Ashworth. 2013. Determinants of Representation: An Empirical Assessment of the UK Civil Service. Policy \& Politics 42 (3): 429-448.

Andrews, R., and R. Ashworth. 2015. Representation and Inclusion in Public Organizations: Evidence from the UK Civil Service. Public Administration Review 75 (2): 279-288.

Andrews, R., R. Ashworth, and K.J. Meier. 2014. Representative Bureaucracy and Fire Service Performance. International Public Management Journal 17 (1): 1-24.

Annesley, C., and F. Gains. 2010. The Core Executive: Gender Power and Change. Political Studies 58 (5): 909-1002.

Annesley, C., and F. Gains. 2012. David Cameron's 'Problem' with Women: Representing Women in the Coalition Government. The Political Quarterly 83-84: 718-725. 
Annesley, C., and F. Gains. 2014. Can Cameron Capture Women's Votes? The Gendered Impediments to a Conservative Majority in 2015. Parliamentary Affairs 67 (4): 767-782.

Bagilhole, B. 2002. Women in Non-traditional Occupations: Challenging Men. Basingstoke: Palgrave Macmillan.

Beckwith, K. 2007. Numbers and Newness: The Descriptive and Substantive Representation of Women. Canadian Journal of Political Science 40 (1): 27-49.

Beckwith, K., and K. Cowell-Meyers. 2007. Sheer Numbers: Critical Representation Thresholds and Women's Political Representation. Perspectives on Politics 5 (3): 553-565.

Blum, T.C., D.L. Fields, and J.S. Goodman. 1994. Organization-Level Determinants of Women in Management. Academy of Management Journal 37 (2): 241-268.

Brecknell, S. 2013. Spot the Difference. https://www.civilserviceworld.com/spot-the-difference. Accessed 17 April 2014.

Burch, M., and I. Holliday. 2004. The Blair Government and the Core Executive. Government and Opposition 39 (1): 1-21.

Cabinet Office. 1999. Modernising Government (Cm 4310). London: HMSO.

Cabinet Office. 2008. Promoting Equality, Valuing Diversity: A Strategy for the Civil Service. London: Cabinet Office.

Cabinet Office. 2014. Diversity \& Inclusion in the Civil Service. Paper presented at Civil Service Live 2014, Newcastle, 3 July 2014.

Cabinet Office. 2015. Permanent Secretary Diversity and Inclusion Objectives. https://www.scribd.com/ document/282695045/Permanent-Secretary-Diversity-Objectives-2015.

Chaney, P. 2002. Women and the Post-devolution Equality Agenda in Wales. A Paper Presented to the Gender Research Forum, Women and Equality Unit, Cabinet Office 11th February 2002.

Chappell, L. 2004. Feminist Engagement with Federal Institutions: Opportunities and Constraints for Women's Multilevel Citizenship. In Representation and Democratic Theory, ed. D. Laycock, 65-89. Vancouver: UCB Press.

Chappell, L. 2013. The State and Governance. In The Oxford Handbook on Gender and Politics, eds. G. Waylen, L. Weldon, K. Celis, and J. Kantola. Oxford: Oxford University Press.

Childs, S., and M.L. Krook. 2008. Critical Mass Theory and Women's Political Representation. Political Studies 56 (3):725-36.

Childs, S., and M.L. Krook. 2009. Analysing Women's Substantive Representation: From Critical Mass to Critical Actors. Government and Opposition 44: 125-45.

Civil Service. 1994. Continuity and Change (Cm 2627). London: HMSO.

Civil Service Commission. 2014. Annual Report and Accounts 2013/14, HC 294. https://assets.publi shing.service.gov.uk/government/uploads/system/uploads/attachment_data/file/322971/2902194_ CSC_Annual_Report_PRINT.PDF. Accessed 15 January 2015.

Civil Service World [CSW]. 2013. Taking the Fast Train Out of Westminster. http://civilservicewor ld.com/taking-the-fast-train-out-of-westminster. Accessed 5 November 2014.

Civil Service World. 2017. First Ever Whitehall Gender Pay Gap Survey Reveals Department for Transport Has Biggest Differential. 19 December 2017 https://www.civilserviceworld.com/articles/ news/first-ever-whitehall-gender-pay-gap-survey-reveals-department-transport-has-biggest.

Cabinet Office. 2015. Civil Service Yearbook 2015. London: Dandy Booksellers.

Connell, R. 2006. Glass Ceilings or Gendered Institutions? Mapping the Gender Regimes of Public Sector Worksites. Public Administration Review 66 (6): 837-849.

Cooper, D., M. Gable, and A. Austin. 2012. The Public-Sector Jobs Crisis. Women and African Americans Hit Hardest by Job Losses in State and Local Governments. Washington: Economic Policy Institute, Briefing Paper \#339.

Dahlerup, D. 2006. The Story of the Theory of Critical Mass. Politics \& Gender 2 (4): 511-522.

Devanny, J., and C. Haddon. 2015. Women in Whitehall: Gender and the Civil Service Since 1979. London: Institute for Government.

Diamond, P. 2014. A Crisis of Whitehall. In Institutional Crisis in 21st Century Britain, eds. D. Richards, Smith and C. Hay. Basingstoke: Palgrave.

Dolan, J. 2000. The Senior Executive Service: Gender, Attitudes, and Representative Bureaucracy. Journal of Public Administration Research and Theory 10 (3): 513-530.

Dolan, J. 2001. Women in the Executive Branch: A Review Essay of their Political Impact and Career Opportunities. Women \& Politics 22 (4): 89-104.

Dugher, M. 2014. The Government Have "Lost Sight of the Diversity Agenda in the Civil Service"Labour Will Sort It Out, 22nd July. https://labourlist.org/2014/07/the-government-have-lost-sight 
-of-the-diversity-agenda-in-the-civil-service-labour-will-sort-it-out-says-dugher/. Accessed 21 November 2014.

Dunton, J. 2017. Brexit Negotiations: David Davis Defends DExEU Team's Gender Balance. Civil Service World, 10 August 2017. https://www.civilserviceworld.com/articles/news/brexit-negotiationsdavid-davis-defends-dexeu-teams-gender-balance. Accessed 11 October 2017.

Flinders, M., C. Skelcher, K. Dommett, and K. Tonkiss. 2013. The Future of the Civil Service. Public Administration Committee, 8 March 2013, HC 74 2013-2014.

Foster, M. 2016a. Labour Warns Glass Ceiling Has Been "painstakingly reassembled" in Wake of Latest Male Perm Sec Appointment. Civil Service World, 11 May 2016. http://civilserviceworld.com/artic les/news/labour-warns-glass-ceiling-has-been-painstakingly-reassembled-wake-latest-male-perm.

Foster, M. 2016b. Jeremy Heywood: Perm sec gender balance not good enough—but pipeline of leaders is there. Civil Service World, 16 May 2016. http://www.civilserviceworld.com/articles/news/jerem y-heywood-perm-sec-gender-balance-not-good-enough-percentE2percent80percent93-pipelineleaders-there?utm_medium=email\&utm_campaign=CSW\%20. Accessed 11 April 2017.

Freeguard, G., E. Andrews, D. Devine, R. Munro, and J. Randall. 2015. Whitehall Monitor: The Coalition in 163 Charts. https://www.instituteforgovernment.org.uk/publications?field_themes_tid=86. Accessed 27 March 2017.

Freeguard, G., R. Adam, E., Andrews, and A. Boon. 2017. Whitehall Monitor 2017. https://www.insti tuteforgovernment.org.uk/publicaccessedwhitehall-monitor-2017. Accessed 8 January 2018.

Government Equalities Office. 2010. Women's Representation, http://webarchive.nationalarchives.gov. uk/20100505211508/http:/www.equalities.gov.uk/pdf/301611_GEO_WomensRepresentation_acc. pdf. Accessed 15 January 2015.

Grey, S. 2002. Does Size Matter? Critical Mass and New Zealand's Women MPs. Parliamentary Affairs: A Journal of Representative Politics 55 (1): 19-29.

Grey, S. 2006. Numbers and Beyond: The Relevance of Critical Mass in Gender Research. Politics \& Gender 2 (4): 492-502.

Halsey, A.H., and I.M. Crewe. 1969. The Civil Service, Vol. 3(1), Surveys and Investigations: Social Survey of the British Civil Service. London: HMSO.

Hay Group. 2014. Women in Whitehall: Culture, Leadership, Talent: Creating an Environment for Talented Women to Succeed. Final Report. London: Cabinet Office.

Healey, S. 2014. Women in the Top 200: Creating Diverse Leadership for the Civil Service. London: DCMS (internal memorandum).

Hennessy P. 1989. Whitehall. London: Fontana.

Heywood, J. 2014. Publication of the Civil Service Talent Action Plan. https://civilservice.blog.gov. uk/2014/09/05/publication-of-the-civil-service-talent-action-plan/. Accessed 15 January 2015.

Hindera, J.J., and C.D. Young. 1998. Representative Bureaucracy: The Theoretical Implications of Statistical Interaction. Political Research Quarterly 51 (3): 655-671.

HM Treasury. 2004. 2004 Spending Review: Public Service Agreements 2005-2008 (Cm 6238). London: HMSO.

Jenkins, K. 2012. Balancing Gender at the Top. The Political Quarterly 83 (4): 726-729.

Kanter, R.M. 1977. Men and Women of the Corporation. New York: Basic Books.

Kavanagh, D., and D. Richards. 2003. Prime Ministers, Ministers and Civil Servants in Britain. Comparative Sociology 2 (1): 175-195.

Kenny, M. 2013. Gender and Political Recruitment: Theorizing Institutional Change. Basingstoke: Palgrave Macmillan.

Kemp-Jones, E.M. 1971. The Employment of Women in the Civil Service: The Report of a Departmental Committee. London: HMSO.

Krislov, S. 1974. Representative bureaucracy. Englewood Cliffs: Prentice-Hall.

Lawrence T., R. Suddaby, and B. Leca. 2011. Institutional Work: Actors and Agency in Institutional Studies of Organizations. Cambridge: Cambridge University Press.

Lily, A. 2017. Civil service gender balance in 2016. Institute for Government https://www.instituteforgov ernment.org.uk/blog/civil-service-gender-balance-2016. Accessed 23 August 2018.

Lipsky, M. 1980. Street-Level Bureaucracy: Dilemmas of the Individual in Public Service. New York: Russell Sage Foundation.

Lombardo, E., and P. Meier. 2018. Good Symbolic Representation: The Relevance of Inclusion. Politics Symposium 2018: 328-330.

Lovecy, J. 2007. Framing Claims for Women: From 'Old' to 'New' Labour. In Women and New Labour: Engendering Politics and Policy, eds. Annesley and F. Gains, 63-92. 
Lovenduski, J. 2005. State Feminism and the Political Representation of Women. Cambridge: Cambridge University Press.

Lovenduski, J. 2008. State Feminism and Women's Movements. West European Politics 31 (1/2): 169-194.

Lovenduski, J., and P. Norris. 2003. Westminster Women: The Politics of Presence. Political Studies 51 (1): 84-102.

Lowe, R. 2011. The Official History of the British Civil Service: Reforming the Civil Service, Volume I: The Fulton Years 1966-81. London: Routledge.

Lowndes, V. 2014. How are Things Done Around Here? Uncovering Institutional Rules and Their Gendered Effects. Politics and Gender 10 (4): 685-691.

Macpherson, N. 2010. Speech by the Permanent Secretary to the Treasury, Sir Nicholas Macpherson, at the 'Unlocking the Senior Civil Service' Conference. https://www.gov.uk/government/speeches/ speech-by-the-permanent-secretary-to-the-treasury-sir-nicholas-macpherson-at-the-unlocking-thesenior-civil-service-conference. Accessed 10 June 2014.

Mansbridge, J. 1999. Should Blacks Represent Blacks and Women Represent Women? A Contingent" Yes". The Journal of Politics 61 (3): 628-657.

Marsh, D., D. Richards, and M.J. Smith. 2001. Changing Patterns of Governance in the United Kingdom: Reinventing Whitehall? London: Macmillan.

Marsh, D., D. Richards, and M. Smith. 2003. Unequal Plurality: Towards an Asymmetric Power Model of British Politics. Government and opposition 38 (3):306-332.

Marvel, J.D., and W.G. Resh. 2015. Bureaucratic Discretion, Client Demographics, and Representative Bureaucracy. The American Review of Public Administration 45 (3): 281-310.

Meier, K.J. 1993. Representative Bureaucracy: An Empirical Analysis. American Political Science Review 69 (2): 373-407.

Meier, K.J., and J. Bohte. 2001. Structure and Discretion: Missing Links in Representative Bureaucracy. Journal of Public Administration Research and Theory 11 (4): 455-470.

Meier, K.J., and J. Nicholson-Crotty. 2006. Gender, Representative Bureaucracy, and Law Enforcement: The Case of Sexual Assault. Public Administration Review 66 (6): 850-860.

Miller, K.J., and D. McTavish. 2014. Representative Bureaucracy: A Typology of Normative Institutional Strategies for the Representation of Women. Policy \& Politics 42 (4): 531-546.

Moran, M. 2003. The British Regulatory State: High Modernism and Hyper-Innovation: High Modernism and Hyper-Innovation. Oxford: Oxford University Press.

Mosher, F.C. 1968. Democracy and the Public Service. New York: Oxford University Press.

Naff, K.C. 1994. Through the Glass Ceiling: Prospects for the Advancement of Women in the Federal Civil Service. Public Administration Review 54 (6): 507-514.

National Audit Office. 2015. Cabinet Office and Cross-Government: Equality, Diversity and Inclusion in the Civil Service, 25 June 2015. www.nao.org.uk/wp-content/uploads/2015/06/Equality-diversityand-inclusion-in-the-civil-service.pdf. Accessed 13 March 2016.

Newman, J., and R.E. Ashworth. 2009. Changing Equalities: Politics, Policies and Practice. In Public Management and Governance, eds. T. Bovaird and E. Loeffler, 203-212. London: Routledge.

Office for National Statistics [ONS]. 2005. Civil Service Statistics 2005. http://webarchive.nationalar chives.gov.uk/20110405163222/http://www.civilservice.gov.uk/about/resources/stats-archi ve/2005-annualreport/2005-annual-report.aspx. Accessed 11 May 2015.

Office for National Statistics [ONS]. 2013. Who is a Typical Civil Servant Today? http://www.ons.gov. uk/ons/rel/pse/civil-service-statistics/2013/sty-civil-service-statistics.html. Accessed 11 May 2015.

Office for National Statistics [ONS]. 2014. Civil Service Statistics 2014. http://www.ons.gov.uk/ons/publi cations/re-reference-tables.html?edition=tcm\%3A77-375368. Accessed 11 May 2015.

Office for National Statistics [ONS]. 2015. Civil Service Statistics, 2015. https://www.ons.gov.uk/emplo ymentandlabourmarket/peopleinwork/publicsectorpersonnel/bulletins/civilservicestatistics/201510-08. Accessed 11 May 2015.

Panchamia, N., and P. Thomas. 2013. Bringing In and Bringing on Talent. London: Institute for Government.

Paun, A., J. Harris, and I. Magee. 2013. Permanent Secretary Appointments and the Role of Ministers. https://www.instituteforgovernment.org.uk/sites/default/files/publications/Permanent\%20secretar y\%20appointments\%20and\%20the\%20role\%20of\%20ministers.pdf. Accessed 7 Jan 2016.

Paun, A., and S. Halifax. 2012. A Game of Two Halves: How Coalition Governments Renew Mid-term and Last the Whole Term. London: Institute for Government.

Phillips, A. 1995. The Politics of Presence. Oxford: Oxford University Press. 
Phillips, A. 1998. Democracy and Representation: Or, Why Should It Matter Who Our Representatives Are? In Feminism and Politics, ed. A. Philips, 224-240. Oxford: Oxford University Press.

Pitkin, H. 1967. The Concept of Representation. Berkeley, CA: University of California Press.

Rafferty, A. 2014. Gender Equality and the Impact of Recession and Austerity in the UK. Revue de l'OFCE 2: 335-361.

Rees, T. 2006. Reflections on the Uneven Development of Gender Mainstreaming in Europe. International Feminist Journal of Politics 7 (4): 555-574.

Rees, J. 2013. Interview: Jonathan Rees (Interviewer: Matt Ross), 8th February 2013. Civil Service World. http://www.civilserviceworld.com/interview-jonathan-rees. Accessed 15 June 2015.

Rhodes, R.A.W. 1995. From Prime Ministerial Power to Core Executive. In Prime Minister, Cabinet and Core Executive, eds. R.A.W. Rhodes and P. Dunleavy, 11-37. London: Palgrave.

Rhodes, R.A.W. 2011. Everyday Life in British Government. Oxford: Oxford University Press.

Riccucci, N.M., and M.K. Meyers. 2004. Linking Passive and Active Representation: The Case of Frontline Workers in Welfare Agencies. Journal of Public Administration Research and Theory 14 (4): 585-597.

Richards, D. 1997. The Civil Service Under the Conservatives 1979-1997: Whitehall's Political Poodles?. Brighton: Sussex Academic Press.

Richards, D. 2008. New Labour and the Civil Service: Reconstituting the Westminster Model. Basingstoke: Palgrave Macmillan.

Richards, D., and M.J. Smith. 2016. The Westminster Model and the Indivisibility of the Political and Administrative Elite: A Convenient Myth Whose Time Is Up. Governance 10: 499-516.

Ross, M. 2014. Interview: Sir Paul Jenkins, Civil Service World 20 March 2014. https://www.civilservi ceworld.com/interview-sir-paul-jenkins. Accessed 15 June 2015.

Saward, M. 2006. The Representative Claim. Contemporary Political Theory 5 (3): 297-318.

Smith, M. 1999. The Core Executive. Basingstoke: Palgrave.

Smith, M., D. Richards, A., Geddes, and H. Mathers. 2011. Analysing Policy Delivery In the United Kingdom: The Case of Street Crime and Anti-social Behaviour. Public Administration 89 (3): 975-1000.

Soni, V. 2000. A 21st Reception for Diversity in the Public Sector: A Case Study. Public Administration Review 60 (5): 395-408.

Sowa, J.E., and S.C. Selden. 2003. Administrative Discretion and Active Representation: An Expansion of the Theory of Representative Bureaucracy. Public Administration Review 63 (6): 700-710.

Squires, J., and M. Wickham-Jones. 2002. Mainstreaming in Westminster and Whitehall: From Labour's ministry for women to the Women and Equality Unit. Parliamentary Affairs 55 (1): 57-70.

Squires, J., and M. Wickham-Jones. 2004. New Labour, Gender Mainstreaming and the Women and Equality Unit. The British Journal of Politics and International Relations 6 (1): 81-98.

Stanley, M. 2014. Civil Service Numbers. http://www.policy.manchester.ac.uk/resources/civilservant/ information/civilservicenumbers/. Accessed 21 November 2014.

Stokes, W. 2005. Women in Contemporary Politics. Cambridge: Polity Press.

Studlar, D.T., and I. McAllister. 2002. Does a Critical Mass Exist? A Comparative Analysis of Women's Legislative Representation Since 1950. European Journal of Political Research 41 (2): 233-253.

Tremblay, M. 2006. The Substantive Representation of Women and PR: Some Reflections on the Role of Surrogate Representation and Critical Mass. Politics \& Gender 2 (4): 502-511.

Watson, S. 1994. Producing the Right Sort of Chap: The Senior Civil Service as an Exclusionary Culture. Policy \& Politics 22 (3): 211-222.

Waylen, G., and L. Chappell. 2013. Gender and the Hidden Life of Institutions. Public Administration 91 (3): 599-615.

Wilkins, V.M. 2006. Exploring the Causal Story: Gender, Active Representation, and Bureaucratic Priorities. Journal of Public Administration Research and Theory 17 (1): 77-94.

Wolf, A. 2013. The XX Factor: How Working Women are Creating a New Society. London: Profile Books.

Women and Equality Unit. 2006. Gender Equality PSA SR04 Delivery Plan. http://webarchive.nationalar chives.gov.uk/20060715214443/http://www.womenandequalityunit.gov.uk/publications/geneq ualpsa_sr04plan.pdf. Accessed 9 April 2017.

Women and Equalities Committee. 2016. Women in Executive Management, 28 June 2016, HC 92 2016-2017. 
Women and Work Commission. 2006. Shaping a Fairer Future. http://webarchive.nationalarchives.gov. uk/20100212235759/http:/www.equalities.gov.uk/pdf/297158_WWC_Report_acc.pdf. Accessed 10 April 2015.

Publisher's Note Springer Nature remains neutral with regard to jurisdictional claims in published maps and institutional affiliations. 